\title{
Study on Water Resistance of Environmentally Friendly Magnesium Oxychloride Cement for Waste Wood Solidification
}

\author{
Feng-Jun Zhang*,**,†, Xian-Yang Sun*, Xuan Li*, Dan Zhang*, \\ Wen- Jie Xie**, Jin Liu ${ }^{* * *}$, and Won-Chun Oh***** \\ *Anhui Key Laboratory of Advanced Building Materials, Anhui Jianzhu University, Hefei Anhui 230022, P. R. China \\ **Key Laboratory of Functional Molecule Design and Interface Process, Anhui Jianzhu University, Hefei Anhui 230601, P. R. China \\ ***Department of Advanced Materials Science \& Engineering, Hanseo University, Seosan 31962, Korea
}

(Received May 1, 2018; Revised July 6, July 19, 2018; Accepted July 19, 2018)

\begin{abstract}
In this study, different formulations of magnesium oxide and various modifiers (phosphoric acid, ferrous sulfate, pure acrylic emulsion, silicone acrylic emulsion, glass fiber, and polypropylene fiber) were used to prepare magnesium oxychloride cement composites. The compressive strength of the magnesium oxychloride cement was tested, and the softening coefficients of the composites after soaking in water were also calculated. The results showed that a magnesium oxychloride cement sample could not be coagulated when the $\mathrm{MgO}$ activity was $24.3 \%$, but the coagulation effect of the magnesium oxide cement sample was excellent when the $\mathrm{MgO}$ activity was $69.5 \%$. While pure acrylic emulsion, silicon-acrylic emulsion, and glass fiber showed insignificant modification effects on the magnesium oxychloride cement, ferrous sulfate heptahydrate, phosphoric acid, and polypropylene fiber could effectively improve its water resistance and compressive strength. When the phosphoric acid, ferrous sulfate heptahydrate, and polypropylene fiber contents were $0.47 \%, 0.73 \%$, and $0.25 \%$, respectively, the softening coefficient of a composite soaked in water reached 0.93 after 7 days, and the compressive strength reached $64.3 \mathrm{MPa}$.
\end{abstract}

Keywords: Magnesium oxychloride cement, Polypropylene fiber, Water resistance, Compressive strength, Waste wood

\section{Introduction}

$I_{\text {n }}^{n}$ recent years, the recycling of waste materials has become a hot issue, ${ }^{1)}$ and the selection of an environmentally friendly inorganic gelling agent and waste board is an effective way to recover waste wood. Composite boards made of waste wood and cementitious materials with excellent mechanical properties are widely used in the furniture and decoration industries. ${ }^{2)}$ As an inorganic cementitious material, magnesium oxychloride cement has excellent fireproof performance. In comparison with traditionally bonded boards that use organic binders, a composite board has the advantages of no harmful gas and a high compressive strength. Thus, magnesium oxychloride cement is considered a better cementitious material. ${ }^{3)}$ However, the poor water resistance of magnesium oxychloride cement has limited its use.

Magnesium oxychloride cement is a special type of cement. It was invented by the Frenchman Stanislas Sorel in 1867. Thus, it is also called Sorrel cement. ${ }^{4}$ It is made by mixing three substances $\left(\mathrm{MgO}, \mathrm{MgCl}_{2}\right.$, and $\left.\mathrm{H}_{2} \mathrm{O}\right)$ according

\footnotetext{
${ }^{\dagger}$ Corresponding author: Feng-Jun Zhang

E-mail : fjzhang@ahjzu.edu.cn

Tel : +86-0551-63828262 Fax : +86-0551-63828106

"Corresponding author: Won-Chun Oh

E-mail : wc_oh@hanseo.ac.kr

Tel : +82-41-660-1337 Fax : +82-41-688-3352
}

to a pre-designed formula. The strength of magnesium oxychloride cement comes from the $\mathrm{MgO} / \mathrm{MgCl}_{2} / \mathrm{H}_{2} \mathrm{O}$ ternary composite crystal salt formed by the reaction of these three basic materials. The main crystalline phases are $3 \mathrm{MgO} \cdot \mathrm{MgCl}_{2} \cdot 8 \mathrm{H}_{2} \mathrm{O}$ (abbreviated as the 318 phase) and $5 \mathrm{MgO} \cdot \mathrm{MgCl}_{2} \cdot 8 \mathrm{H}_{2} \mathrm{O}$ (abbreviated as the 518 phase), while $\mathrm{Mg}(\mathrm{OH})_{2}$ exists mainly in a gel state, and the usual components of magnesium oxychloride cement are the above three substances. In order to understand the formation of magnesium oxychloride cement from a thermodynamic point of view, researchers have studied the reaction system components, curing temperature, and proportions of the final cement block, ${ }^{5)}$ along with the influences of the composition, ratio of the components, and formation of the crystalline phase. ${ }^{6}$ ) Although magnesium oxychloride cement has the advantages of a fast setting speed and excellent adhesive performance, its poor water resistance greatly affects the further development of magnesium oxychloride cement products. Experiments have proven that the addition of an admixture can effectively improve the water resistance of magnesium oxychloride cement. Researchers have added $\mathrm{FeSO}_{4}{ }^{7}{ }^{7}$ fly ash, ${ }^{8,9}$ incineration sludge ash, ${ }^{10)}$ phosphoric acid, ${ }^{11,12)}$ and rice hull ash $^{13)}$ and have significantly improved its water resistance. However, because the compressive strength has simultaneously been reduced, it is clear that an admixture alone cannot improve the overall performance. A mixture of two species or two or more admixtures can improve the overall performance. 
In this study, the effects of different molar ratios of $\mathrm{MgO} /$ $\mathrm{MgCl}_{2}$ and different additives on the comprehensive performance of magnesium oxychloride cement were investigated. Polypropylene fibers, which have a high toughness and mechanical strength, were added to magnesium oxychloride cement for the first time, and the curing conditions were also researched. ${ }^{14,15)}$ The ternary composite modification method was adopted to simultaneously improve the compressive strength and water resistance of the magnesium oxychloride cement.

\section{Experimental Procedure}

\subsection{Materials}

The materials used included light burned magnesia powder with an activity of $24.3 \%$, supplied by Gaoyi County Chemical Plant, Hebei Province, China (Hebei, China); light burned magnesia powder with an activity of $69.5 \%$, supplied by Shandong Shouguang Bonze Chemical Co., Ltd. (Shandong, China), magnesium chloride hexahydrate $\left(\mathrm{MgCl}_{2} \cdot 6 \mathrm{H}_{2} \mathrm{O}\right)$, supplied by Shandong Shouguang Guangbang Ze Chemical Co., Ltd. (Shandong, China); phosphoric acid, AR (Shanghai test); polypropylene fiber, supplied by Shenzhen Tiandu Technology Co., Ltd. (Shenzhen, China); ferrous sulfate heptahydrate, AR (Shanghai test); pure acrylic emulsion, AR (Shanghai test); silicone acrylic emulsion, AR (Shanghai test); glass fiber, supplied by Changzhou Lingteng Composite Material Co., Ltd. (Jiangsu, China); and laboratory tap water.

\subsection{Different preparation formulations of magne- sium oxychloride cement}

The molar ratio of $\mathrm{n}(\mathrm{MgO}): \mathrm{n}\left(\mathrm{MgCl}_{2}\right)=6: 1$ and 10.15:1 (hereinafter referred to as formula 1 and formula 2, respectively) were used, along with a molar ratio of $\mathrm{n}\left(\mathrm{MgCl}_{2}\right): \mathrm{n}$ $\left(\mathrm{H}_{2} \mathrm{O}\right)=1: 14$. Magnesium chloride hexahydrate and water were weighed to prepare a solution for use, and then $\mathrm{MgO}$ was added to the mixer (the heptahydrate ferrous sulfate and liquid additives were first dissolved in the magnesium chloride solution, then $\mathrm{MgO}$ powder was add, with the final addition of solid additives). After stirring (slow stirring for 3

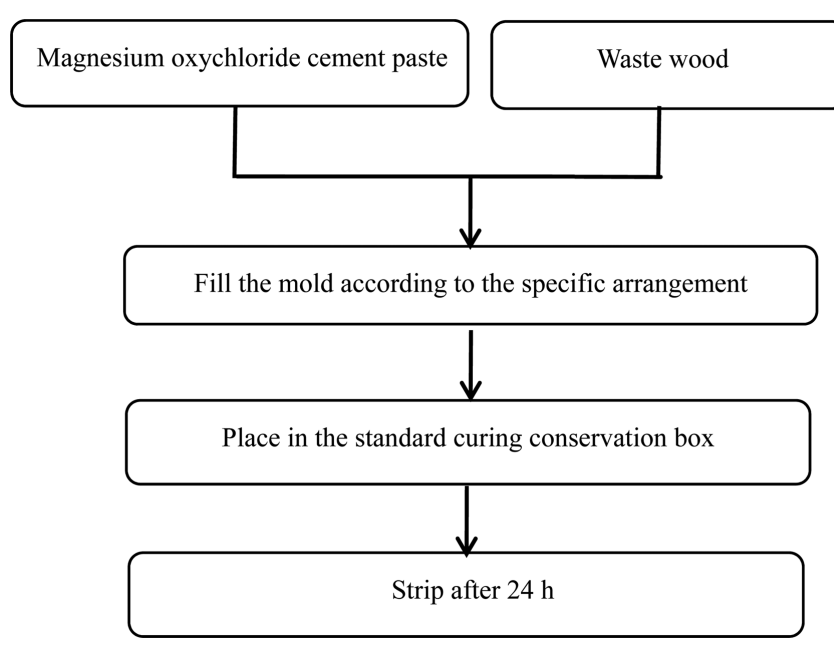

Fig. 1. Flow chart for preparation of composite wood.

min, and rapid stirring for $1 \mathrm{~min}$ ), the uniform slurry was placed in a $40 \mathrm{~mm} \times 40 \mathrm{~mm} \times 160 \mathrm{~mm}$ triple-linked mold, which was stripped after $24 \mathrm{~h}$ in a standard curing box. A group of samples was maintained in water for 7 days, and the others were maintained in batches for 3 days and 7 days under dry conditions (all samples were kept within the standard curing box).

\subsection{Preparation of magnesium oxychloride cement and waste wood composite}

First, the modified magnesium oxychloride cement slurry was prepared, and then the cement and wood were placed in the mold according to the flow diagram and schematics in Figs. 1-3.

The detailed preparation process was as follows:

The waste wood order was arranged as shown in Fig. 3. First the magnesium oxychloride cement slurry (approximately $4 \mathrm{~mm}$ ) was poured into a $40 \mathrm{~mm} \times 40 \mathrm{~mm} \times 160 \mathrm{~mm}$ triple-linked mold, and the wood was arranged according to Fig. 3(a). Then, more of the magnesium oxychloride cement slurry (approximately $4 \mathrm{~mm}$ ) was poured on the wood, and more wood was arranged according to Fig. 3(b). Next, more of the magnesium oxychloride cement slurry (approximately
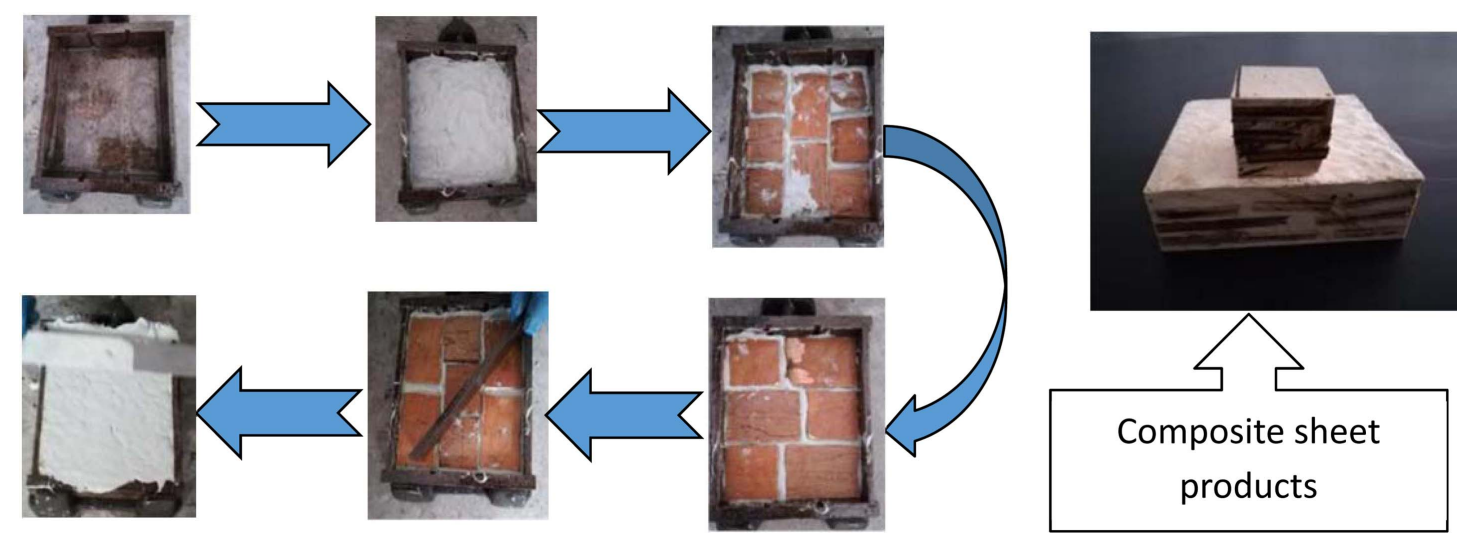

Fig. 2. Schematic diagram for preparation of composite wood. 

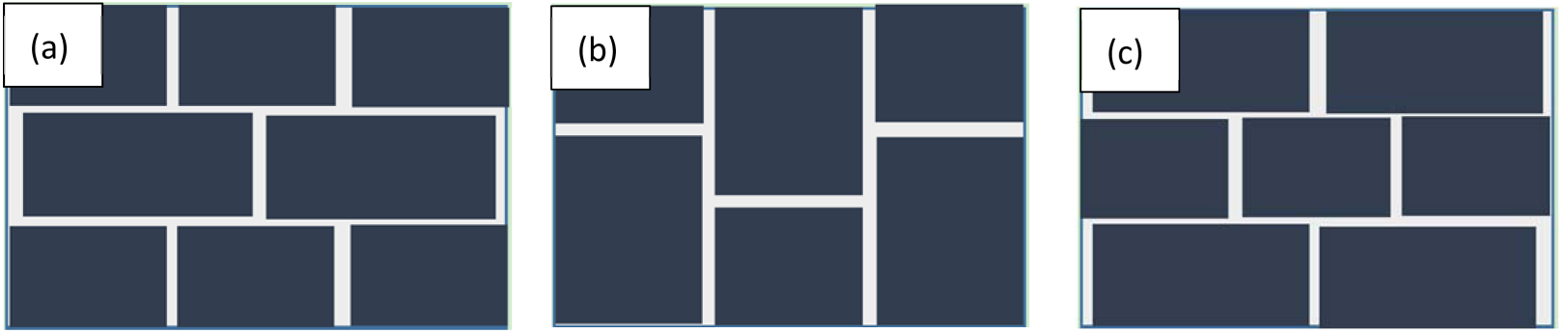

Fig. 3. Schematic illustration of waste wood order.

$4 \mathrm{~mm}$ ) was poured on the wood, and more wood was arranged as shown in Fig. 3(c). Finally, a top layer of magnesium oxychloride cement slurry was poured, and the surface was smoothed.

\subsection{Characterization}

Cement mortar was mixed with NJ-160A cement paste mixer, a cement block was trimmed with an STG-1 concrete cutter, and the compressive strength of the cement sample was tested using an NYL-600 type pressure tester. The microstructure of the magnesium oxychloride cement was observed using a YH-40C Electrical Display Standard Maintenance Box and a JSM-7500F scanning electron microscope (SEM).

The activity of the magnesium oxide was determined using the following method.

First, $100 \mathrm{~g}$ of magnesia was accurately weighed in a constant weight dry beaker, and $400 \mathrm{~g}$ of water was added, making it completely wet. It was then heated to boiling in an electric furnace for $2 \mathrm{~h}$, after which the beaker was removed from the $150^{\circ} \mathrm{C}$ oven and dried to a constant weight.

Magnesium oxide activity content $=(A-100) / 45 \times 100 \%$

In this formula, $\mathrm{A}$ is the sample quality after hydration.

The strength of the sample is in accordance with the G / B 17671--1999 "Standard Test Method for Cement Mortar Strength (ISO)." The softening coefficient reference JG / T 1169--2005 "Lightweight slats for building partitions" was used for the determination of the softening coefficient:
$\mathrm{I}=\mathrm{R}_{1} / \mathrm{R}_{0}$

In this formula, $R_{1}$ is the bubble water seven days average compressive strength, and

$R_{0}$ is the average dry block seven days compressive strength.

\section{Results and Discussion}

\subsection{Influence of different additives and formula- tions on the performance of the sample}

The additives included phosphoric acid, ferrous sulfate heptahydrate, and polypropylene fiber, and the adding method was singly or repeated mixing. The amount of doping with phosphoric acid and ferrous sulphate was based on the references, ${ }^{4,11,12)}$ and combined with the setting experiment. The effects of the different additives are listed in Table 1.

As listed in Table 1, Formula 1 was used and modified with additives such as phosphoric acid, ferrous sulfate heptahydrate, and silicone-acrylate emulsion. When phosphoric acid was added, the early compressive strength of the sample was lower than that of the blank sample, but the softening coefficient was greatly increased. Obviously, the water resistance of the sample after the modification was greatly improved, because phosphate and magnesium ions are capable of forming a water-insoluble salt on the surface of the compressive strength source 518 phase, which isolated the water and protected the 518 phase. However, because of the wrapping state, which also limited the growth of the 518 phase, the macroscopic appearance was

Table 1. Formula I - Influence of Additives on the Performance of the Sample*

\begin{tabular}{|c|c|c|c|c|c|}
\hline \multirow[b]{2}{*}{ Additive } & \multirow[b]{2}{*}{ Content/wt\% } & \multicolumn{3}{|c|}{ Compressive strength/MPa } & \multirow[b]{2}{*}{$\begin{array}{l}\text { Softening } \\
\text { coefficient }\end{array}$} \\
\hline & & $\begin{array}{r}\text { Three } \\
\text { days }\end{array}$ & $\begin{array}{c}\text { Seven } \\
\text { days }\end{array}$ & $\begin{array}{l}\text { Soaked water } \\
\text { seven days }\end{array}$ & \\
\hline Blank sample & & 35.2 & 38.1 & 13.7 & 0.36 \\
\hline Phosphoric acid & 0.47 & 20.7 & 33.7 & 32.1 & 0.95 \\
\hline Phosphoric acid/silicone acrylic emulsion & $0.47 / 1.02$ & 29.4 & 35.5 & 34.6 & 0.97 \\
\hline Phosphoric acid/ferrous sulfate heptahydrate & $0.47 / 0.73$ & 34.8 & 40.3 & 49.0 & 1.21 \\
\hline Phosphoric acid/pure acrylic emulsion & $0.47 / 1.02$ & 25.9 & 34.5 & 44.8 & 1.29 \\
\hline Phosphoric acid/silicone acrylic emulsion/glass fiber & $0.47 / 1.02 / 0.51$ & 24.4 & 34.8 & 44.5 & 1.27 \\
\hline
\end{tabular}

*During the experiment, it was found that when the magnesium oxide activity was $24.3 \%$, there was no evidence of coagulation at all after 7 days of curing. Therefore, the following experiment used magnesium oxide with an activity of $69.5 \%$. 
Table 2. Formula II - Influence of Additives on Performance of Sample

\begin{tabular}{|c|c|c|c|c|c|}
\hline \multirow[b]{2}{*}{ Additive } & \multirow[b]{2}{*}{ Content/wt\% } & \multicolumn{3}{|c|}{ Compressive strength/MPa } & \multirow{2}{*}{$\begin{array}{l}\text { Softening } \\
\text { coefficient }\end{array}$} \\
\hline & & $\begin{array}{r}\text { Three } \\
\text { days }\end{array}$ & $\begin{array}{l}\text { Seven } \\
\text { days }\end{array}$ & $\begin{array}{l}\text { Soaked water } \\
\text { seven days }\end{array}$ & \\
\hline Blank sample & & 73.45 & 71.36 & 38.59 & 0.54 \\
\hline Phosphoric acid & $0.37 \%$ & 61.84 & 52.97 & 55.78 & 1.05 \\
\hline Ferrous sulfate heptahydrate & $0.40 \%$ & 77.51 & 63.63 & 34.18 & 0.54 \\
\hline Phosphoric acid/ferrous sulfate heptahydrate & $0.37 \% / 0.40 \%$ & 64.25 & 72.36 & 47.96 & 0.66 \\
\hline Phosphoric acid/polypropylene fiber & $0.37 \% / 0.50 \%$ & 65.24 & 65.96 & 67.62 & 1.02 \\
\hline Phosphoric acid/phosphoric acid/polypropylene fiber & $0.37 \% / 0.40 \% / 0.5 \%$ & 53.78 & 77.6 & 62.75 & 0.81 \\
\hline
\end{tabular}

retarded. From the point of view of enhancing the compressive strength, after $7 \mathrm{~d}$, the compressive strength of the sample modified by phosphoric acid and ferrous sulfate heptahydrate reached $49.03 \mathrm{MPa}$, and the softening coefficient reached 1.21 , because part of the magnesium phosphate was formed at the surface of the 518 phase and was inhibited by the magnesium phosphate coating. In summary, the performance of the samples modified with phosphoric acid and heptahydrate composite ferrous sulfate was better than that of the samples with the other additives, and the results were the same as those described in the literature. Thus far, the purpose of the modification has been achieved.

Table 2 was modified on the basis of the first formula and shows that single doped phosphoric acid can improve the water resistance of the magnesium oxychloride cement, and reduce the early strength, just as shown by the results listed in Table 1. Single doped heptahydrate ferrous sulfate improved the early strength of the magnesium oxychloride cement, but it made no contribution to the water resistance. Because the sulfate and magnesium ions combined in the cement to form salts that contributed to the integral strength of the cement, the magnesium sulfate was readily soluble in water and contributed little to the water resistance of the magnesium oxychloride cement. A mixture with phosphoric acid and ferrous sulfate heptahydrate can increase its early strength and softening coefficient, which was increased by 0.12 compared with the blank sample. It was clear that our desired results for the water resistance were not achieved. However, when polypropylene fiber was added, the results showed that the softening coefficient increased by 0.15 , reaching 0.81 , which was basically the expected modification result.

According to the two tables, the integral compressive strength with formula 2 is higher than that with formula 1 . When the $\mathrm{MgO} / \mathrm{MgCl}_{2}$ molar ratio in formula 1 was $6: 1$, the compounding effect of the phosphoric acid and ferrous sulfate heptahydrate was the best. When the formula was changed to a $\mathrm{MgO} / \mathrm{MgCl}_{2}$ molar ratio of $10.15: 1$, the softening coefficient of the phosphoric acid and ferrous sulfate heptahydrate was only 0.66 . Thus, $0.5 \mathrm{wt} \%$ polypropylene fiber was added, and the softening coefficient was increased to 0.82 . Because the purpose of this study was to improve the compressive strength and water resistance of magnesium oxychloride cement products, a $\mathrm{MgO} / \mathrm{MgCl}_{2}$ molar ratio of $10.15: 1$ was chosen as the best modified base formula.

The SEM image of Fig. 4(a) shows that the rod structure inside the magnesium oxychloride cement is hydrolyzed. The needle and rod structure can be clearly seen in Fig. 4(b), and the film material is attached to the surface of the needle and rod structure. It can be seen from Fig. 4(c) that the gel part inside the magnesium oxychloride cement is connected in series by the fibers. Figs. 5(a) and (b) show pictures of the blank and phosphoric acid/ferrous sulfate/polypropylene fiber modified samples, respectively, after soaking in water for seven days. Table 1 and Figs. 4 and 5 show that when the magnesium oxychloride cement products are not modified, the internal structure of the needle and rod shows hydrolysis, resulting in a sharp decline in the compressive strength of the products. A protective film of magnesium
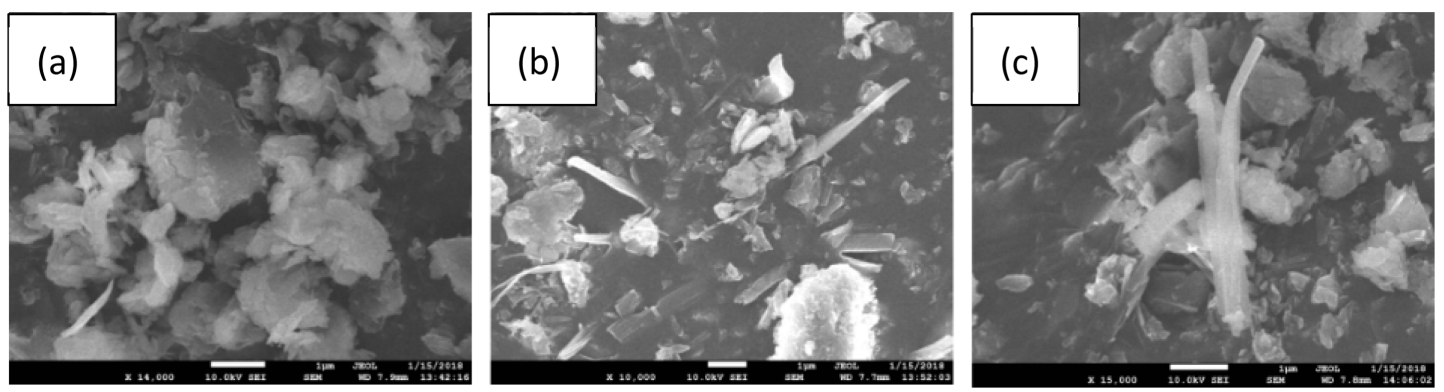

Fig. 4. SEM images of internal surfaces of samples: (a) blank, (b) phosphate modified, and (c) phosphoric acid/ferrous sulfate/ polypropylene fiber composite modified after soaking in water for seven days. 

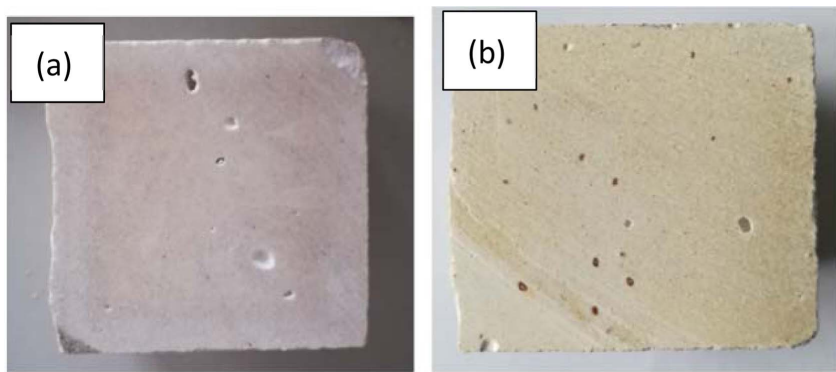

Fig. 5. Sectional drawing of samples: (a) modified composite and (b) unmodified cross-section.

phosphate is formed on the surface of the needle and rod structure to prevent its hydrolysis. When the phosphoric acid/ferrous sulfate/polypropylene fiber is incorporated, the polypropylene fiber inside the magnesium oxychloride cement places amorphous gel-like substances in series, the number of gaps in the magnesium oxychloride cement is decreased, and the density is increased. When combined with the phosphoric acid and heptahydrate ferrous sulfate, the cement product not only has an improved compressive strength but also an improved water resistance.

\subsection{Effects of polypropylene fiber content on perfor-} mance of magnesium oxychloride cement

The previous study explored the positive impact on the water resistance of using polypropylene fiber in magnesium chloride cement samples. In this study, the benefits of using a mixture of phosphate and ferrous sulfate heptahydrate were determined, and polypropylene fiber content gradients of $0.25,0.5,0.75,1,1.25,1.5$, and 1.75 were tested to determine the optimal content of polypropylene fibers.

As shown in Fig. 6 and Fig. 7, the compressive strength increases and then decreases with an increase in the polypropylene fiber content. When the polypropylene fiber content was $0.25 \%$, the compressive strength was $64.3 \mathrm{MPa}$, and the softening coefficient was 0.93 after the sample was maintained for 7 days in water, but the compressive

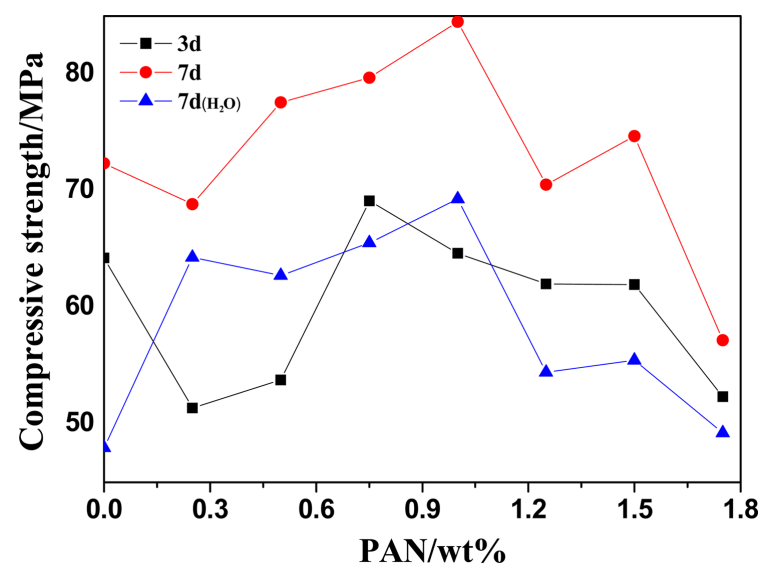

Fig. 6. Effect of polypropylene fiber content on compressive strength of samples.

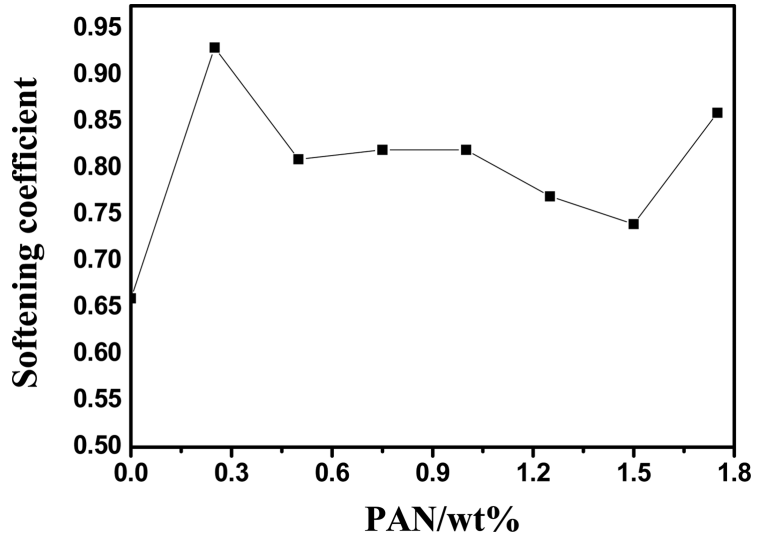

Fig. 7. Effect of polypropylene fiber content on softening coefficient of sample.

strength was not the highest. When the of content polypropylene fiber was 1\%, the compressive strength was 69.3 and the softening coefficient was 0.82 after the sample was maintained for 7 days in water. Thus, the softening coefficient was slightly lower. When the polypropylene fiber content was $0.25 \%$, the magnesium oxychloride cement had the best integral performance. The magnesium oxychloride cement slurry of the formula was compounded with the waste wood board in the mold according to the previously mentioned method, and the compressive strength of composite material reached $51.41 \mathrm{MPa}$ after $7 \mathrm{~d}$, which greatly broadened its application range in the engineering field.

\section{Conclusions}

Because its poor water resistance has limited the use of magnesium oxychloride cement in the engineering field, additive modification has been used to expand its application scope. When phosphoric acid, ferrous sulfate, and polypropylene fiber contents of $0.37 \%, 0.4 \%$, and $0.25 \%$ were added, respectively, the softening coefficient reached 0.93 , and the compressive strength reached $64.3 \mathrm{MPa}$ after 7 days of soaking. When magnesium oxychloride cement was prepared as a gelling agent using this formula and mixed with waste board, the compressive strength reached 51.41 MPa after being stored in a dry environment for seven days.

The experimental results showed that a composite sheet formed using magnesium oxychloride cement to glue waste wood board reached the appropriate water resistance level and had a high strength. It is believed that it has broader application prospects for home decoration composite boards.

\section{Acknowledgments}

This work were financially supported by the Major Projects of Natural Science Research in Anhui Colleges and Universities (KJ2018ZD050), Natural Science Foundation of Anhui province (1808085ME129), Outstanding Young Talents Support Program in Colleges and Universities (gxy- 
qZD2018056), and College Students' Science and Technology Innovation Foundations (2018-242).

\section{REFERENCES}

1. H. N. Cheng, C. Ford, M. K. Dowd, and Z. He, "Soy and Cottonseed Protein Blends as Wood Adhesives," Ind. Crops Prod., 85 324-30 (2016).

2. X. Zhou and Z. Li, "Light-Weight Wood-Magnesium Oxychloride Cement Composite Building Products Made by Extrusion," Constr. Build. Mater., 27 [1] 382-89 (2012).

3. S. Jin, K. Li, J. Li, and H. Chen, "A Low-Cost, Formaldehyde-Free and High Flame Retardancy Wood Adhesive from Inorganic Adhesives: Properties and Performance," Polymers, 9 [10] 513 (2017).

4. S. Sorel, "On a New Magnesium Cement," C. R. Acad. Sci., 65 102-4 (1867).

5. Z. Zhou, H. Chen, Z. Li, and H. Li, "Simulation of the Properties of $\mathrm{MgO}-\mathrm{MgCl}_{2}-\mathrm{H}_{2} \mathrm{O}$ System by Thermodynamic Method," Cem. Concr. Res., 68 105-11 (2015).

6. Z. Liu, M. Balonis, J. Huang, A. Sha, and G. Sant, "The Influence of Composition and Temperature on Hydrated Phase Assemblages in Magnesium Oxychloride Cements," J. Am. Ceram. Soc., 100 [7] 3246-61 (2017).

7. Y. Li, Z. Li, H. Pei, and H. Yu, "The Influence of $\mathrm{FeSO}_{4}$ and $\mathrm{KH}_{2} \mathrm{PO}_{4}$ on the Performance of Magnesium Oxychloride Cement," Constr. Build. Mater., 102 233-38 (2016).

8. C. K. Chau, J. Chan, and Z. Li, "Influences of Fly Ash on
Magnesium Oxychloride Mortar," Cem. Concr. Compos., 31 [4] 250-54 (2009).

9. P. He, S. P. Chi, and D. C. W. Tsang, "Effect of Pulverized Fuel Ash and $\mathrm{CO}_{2}$ Curing on the Water Resistance of Magnesium Oxychloride Cement (MOC)," Cem. Concr. Res., 97 115-22 (2017).

10. P. He, S. P. Chi, and D. C. W. Tsang, "Using Incinerated Sewage Sludge Ash to Improve the Water Resistance of Magnesium Oxychloride Cement (MOC)," Constr. Build. Mater., 147 519-24 (2017).

11. Y. Tan, Y. Liu, and L. Grover, "Effect of Phosphoric Acid on the Properties of Magnesium Oxychloride Cement as a Biomaterial," Cem. Concr. Res., 56 [2] 69-74 (2014).

12. Y. Tan, Y. Liu, Z. Zhao, J. Z. Paxton, and L. M. Grover, "Synthesis and in vitro Degradation of a Novel Magnesium Oxychloride Cement," J. Biomed. Mater. Res. A, 103 [1] 194-202 (2015).

13. K. Xu, J. Xi, Y. Guo, and S. Dong, "Effects of a New Modifier on the Water-Resistance of Magnesite Cement Tiles," Solid State Sci., 14 [1] 10-4 (2012).

14. B. Xu, H. Ma, C. Hu, S. Yang, and Z. Li, "Influence of Curing Regimes on Mechanical Properties of Magnesium Oxychloride Cement-Based Composites," Constr. Build. Mater., 102 613-19 (2016).

15. V. M. Sglavo, F. D. Genua, A. Conci, R. Ceccato, and R. Cavallini, "Influence of Curing Temperature on the Evolution of Magnesium Oxychloride Cement," J. Mater. Sci., 46 [20] 6726 (2011). 